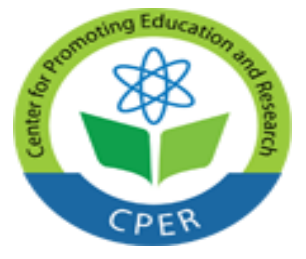

VOL: 5, ISSUE: 3

March/2019

https://ijbassnet.com/

E-ISSN: 2469-6501

(C) Center for Promoting Education and Research (CPER) USA

WWW.cpernet.org

\title{
Development of an Ethics Training Program
}

\author{
Austin Zekeri, MBA, Ph.D \\ Professor of Accounting \& Finance \\ Polk State College \\ Lakeland, Florida \\ E-mail: azekeri@polk.edu \\ USA
}

\begin{abstract}
A+ Accounting seeks to be an ethical business leader, through the implementation of their company code of ethics and ethics training program for employees. Employees shall be trained on the company code of ethics; financial reporting and accounting standards; professional judgment, professional skepticism, and decision making; and on the company's fraud prevention program. Furthermore, employees shall learn internal controls and how to recognize fraud in the workplace, while also giving feedback for adjustments and future trainings. All of which, shall be governed by the company's code of ethics and values, as they are the foundation of $A+$ Accounting.
\end{abstract}

Keywords: ethics, values, fraud, internal controls, compliance, accounting.

\section{Introduction}

Given the unethical behavior witnessed through such scandals as Enron, WorldCom, HealthSouth, and Lehman Brothers, and the damage they caused to companies, shareholders, Wall Street, and the economy, it can be seen that it would be extremely beneficial for a company to have an internal ethics training program. Having an ethics training program lays a strong foundation for a company and clearly communicates what ethical and moral expectations are required from employees. Ethics training programs can also aid in increasing employee morale, confidentiality, and productivity, which subsequently allows an organization to increase profits through the reduction of wasted time, and money lost to fraudulent activities.

\section{Ethics}

Ethics, in philosophy, is that which is considered "good", and is also referred to as "moral philosophy" in the Western tradition of ethics (Mintz \& Morris, 2014). Ethics seeks to develop concepts regarding right vs. wrong, based on accepted standards of behavior. These accepted standards of behavior are generally based on culture or religion, or for the purpose of this paper, a profession that is governed by laws and regulations. Furthermore, ethics requires reasoning to determine the effect that an action will have on others, and one's ability to carry through with that action.

Ethics are an extremely important aspect of a company's workplace. In addition to reducing blatant acts of fraud committed by a few individuals, company ethical standards can also effect office morale, teamwork, and employee performance. Having an ethical office shows that the company is making an effort to show employees (and clients) respect and makes for a positive working environment. It can also reduce pressure and rationalization, two of the three components of the fraud triangle. If an employee is happy at their company, and being treated with respect, they are less likely to feel pressure to submit fraudulent numbers or to rationalize committing fraud against 


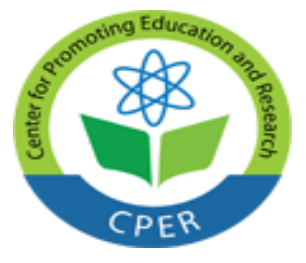

VOL: 5, ISSUE: 3

March/2019

E-ISSN: 2469-6501

(C) Center for Promoting Education and Research (CPER) USA

WWW.cpernet.org

their company if they feel they are being mistreated. Having ethical upper management will subsequently set an ethical "tone at the top" for the company and give employees a good example to follow. In John C. Maxwell's, the 21 Irrefutable Laws of Leadership (2007), law \#14 is the "Law of Buy-In", which states that people buy into a leader first, and then the leader's vision. Thus, a company that is setting a strong ethical "tone at the top" for its employees, is more likely to have its employees follow and buy-in to the tone. Ethical employees, who are in a good situation, will be less likely to enter the components of the fraud triangle and subsequently be less likely to commit a fraudulent act against the company. Ethical employees will assist in increasing office morale and productivity, along with profits (as previously discussed), while also decreasing the fraud occurrences and the negative public image (and consequences) it brings. Thus, it is imperative that every office has, and maintain, an ethics training program. Which is why the following training program is being enacted at A+ Accounting.

\section{Company Code of Ethics}

The A+ Accounting company code of ethics shall be given to all employees and gone over with during their first week on the job. The company code of ethics applies to all employees from the CEO on down and is the foundation for the A+ Accounting company standards. A Code of Ethics Contact is the responsible party for receiving violations and reports and shall be the individual to make sure they are fully investigated. They shall also be the party responsible for overseeing this policy, updating it, and enforcement of it (along with assistance from management).

\section{Core Values}

Core values are important to a company as they provide a sense of belonging and promote loyalty among employees. Additionally, core values are the foundation of a company's culture; without them, one cannot build a long-lasting, sustainable culture (DeHart, 2011). The core values at A+ Accounting shall apply to all, and include honesty, integrity, quality, accountability, respect, and empathy. Honesty shall be shown in A+ Accounting's revelation of the true facts and data to stakeholders. A+ Accounting shall show integrity in the job we do and to our profession. A+ Accounting shall strive for high-quality work and output. A+ Accounting shall be accountable for our actions by taking responsibility for our decisions. A+ Accounting shall show respect for ourselves, our fellow co-workers, stakeholders, our profession, and our company. Finally, A+ Accounting shall show empathy for our coworkers and clients when they are in difficult situations.

\section{Conflicts of Interest}

Conflicts of interest will be defined as ethical problems arising when an employee allows the performance of his or her official duties to be affected by his own personal interest (gain) or outside considerations/associations. Additionally, this would also include an employee's family member benefitting personally as a result of a transaction occurring at the company. An employee's service to the company, and performance of one's job duties, should not be secondary to, or dependent upon, personal gain. Conflicts of interest shall be avoided. Employees shall annually sign Conflicts of Interest Statements each year, stating any possible conflicts of interest they may have with customers or outside associations. If conflicts of interest do arise, they must be reported immediately to the employee's supervisor, and a new form must be completed, signed and put on file, so the conflict may be avoided.

\section{Compliance}

A+ Accounting shall comply with any applicable regulations, laws, and standards associated with the work performed at the company; this includes state, federal, internal, and professional standards, laws, and regulations. The responsibility to comply with such items falls to each individual employee within the company, related to their job description and level of power. Any employee who is aware of non-public information about the company may not use it for personal gain or share with others for their personal gain. Any employee that has a question about the 


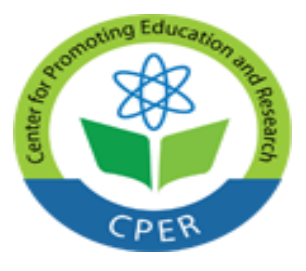

VOL: 5, ISSUE: 3

March/2019

E-ISSN: 2469-6501

(C) Center for Promoting Education and Research (CPER) USA

WWW.cpernet.org

purchase of company securities and/or the violations of the federal securities law, should immediately contact the company's legal department for an explanation.

\section{Gifts from Outside Sources}

A gift is a gratuity, favor, discount, entertainment, hospitality, loan, forbearance, or other item having a monetary value (NIH, 2015). A gift may not be taken directly (to the employee) or indirectly (to an employee's family or friend) from an outside source that is offering the gift due to the employee's position with this company. A gift is not refreshments given with a meal, or snacks at a gathering, or a prize where the contestant pool was open to the general public. A gift is also not an item of low basic value, such as a certificate for participation or card. Any reports of employees receiving gifts from outside sources should be reported to the Code of Ethics Contact.

\section{Consequences}

Any company employee who knows of a violation of the company code of ethics is required to immediately report it to the Code of Ethics Contact. Any questions or concerns pertaining to the code of ethics should be either addressed with the company's legal department or said Code of Ethics Contact (or both). Employees shall not retaliate against others based on reported violations. Reports of violations shall be investigated by the legal department, the Code of Ethics Contact, and the CFO. Reports including the CFO, or a Director will include the head of the Audit committee; report conclusions will be reported to the Audit Committee, who may then inform the Board of Directors. Findings of employees in violation may lead to repayment (monetary, or time, depending on the situation) or termination, and reporting of the incident to the proper authorities.

\section{Financial Reporting \& Accounting Standards}

A+ Accounting strives to be an ethical business, part of which includes showing that their actions speak louder than words. Thus, A+ Accounting not only lists their core values but also lives them (and follows through on them) as well. Three of A+ Accounting's (previously listed) core values include: integrity, quality, and accountability; these values shall be shown through our financial reporting and accounting standards practices.

\section{Financial Reporting}

The books, records and financial statements at A+ Accounting must accurately reflect the company's transactions and provide reasonable detail regarding said transactions. Additionally, they must follow and conform to any state or federal regulation or law. Employees at A+ Accounting are expected to be committed to full discloser of financial information, always within a timely and accurate manner. Employees are obligated to report any unethical transactions or report findings that they are aware of and that would violate any regulation, law or internal policy. Additionally, employees are expected to keep all confidential information as such and safeguard any such transactions. Company documentation shall be kept or destroyed based on the company's retention policy; any inquiries by the government shall be directed to A+ Accounting's Legal Department.

\section{Accounting Standards}

At A+ Accounting, all employees shall use, as a reference, The Federal Accounting Standards Advisory Board (FASAB) Handbook of Accounting Standards and Other Pronouncements, as Amended. The FASAB Handbook compiles and codes the accounting standards and other pronouncements developed by FASAB and incorporates amendments within each individual pronouncement; it is designed to meet the needs of users for an authoritative reference regarding concepts, standards, interpretations and technical bulletins and releases (FASAB,2015). Employees at A+ Accounting are also expected to follow the American Institute of CPAs (AICPA) standards and statements, which include: Audit and Attest Standards, Code of Professional Conduct, Compilation and Review Standards, Consulting Services Standards, Continuing Professional Education (CPE) Programs Standards, Peer Review Standards, Personal Financial Planning Statements, Tax Standards, and Valuation Services Standards. 


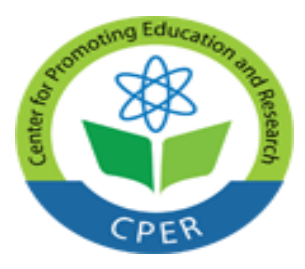

VOL: 5, ISSUE: 3

March/2019

E-ISSN: 2469-6501

(C) Center for Promoting Education and Research (CPER) USA

WWW.cpernet.org

Additionally, employees at A+ Accounting, are also expected to follow the IMA Statement of Ethical Professional Practice, which also goes along with A+ Accounting's own code of ethics. Employees are expected to, on a minimum, annually review the IMA's statement; additionally, it will be incorporated into an annual staff training as part of the ethics training program and as a refresher.

\section{Professional Judgment, Skepticism \& Decision Making}

Making a judgment or decision that is ethical can be difficult for employees, especially if negative consequences could result due to the decision. A+ Accounting seeks to make such decisions easier through support and training to all of its employees. A+ Accounting also strives to instil in its employees the importance of professional skepticism for this company and the profession.

\section{Professional Judgment \& Skepticism}

Professional judgment involves applying relevant training, knowledge, and experience within the context provided by relevant professional and technical standards when it comes to making informed decisions about courses of action that are appropriate in the circumstances (AICPA, 2015). Professional judgment is a skill that is acquired by employees through training and experience. The application of professional judgment is essential in the interpretation of laws, regulations, and standards (Fazel, 2011), and in "grey area" circumstances.

Professional skepticism as defined by the Public Company Accounting Oversight Board (PCAOB), is an attitude that includes a questioning mind and a critical assessment of audit evidence, and it is essential to the performance of effective audits under Board standards (PCAOB, 2012). Having an open and skeptical mind allows an auditor to recognize misstatements that might occur and be able to investigate them without any bias. Professional skepticism allows an auditor to see the big picture, by just looking at the facts, to determine if any mistaken errors have occurred, or intentional fraud.

In order to aid employees in their professional judgment and skepticism, the company shall stream webcasts from the PCAOB, and go over (during training and in memos) PCAOB Alerts on such related topics. Employees are also encouraged to attend AICPA conferences and utilize their Continuing Professional Education (CPE) products, such as self-study courses, live web events or group-study opportunities. Company board members shall also be required to read the Committee of Sponsoring Organizations of the Treadway Commission's (COSO) "Enhancing Board Oversight: Avoiding Judgment Traps and Biases". This document details a five-step process that board members and others can use to improve board oversight of management's judgments by raising board member awareness of important insights that can improve the judgment of experienced executive and board members (COSO, 2012). While it is required for board members, it is also highly suggested to upper management and any other employee with management goals.

\section{Decision Making Process}

To further assist employees in ethical decision making, Rest's four-component model of ethical decision making will be used as a guideline when faced with an ethical dilemma. Rest's model is based on the presumption that an individual's behavior is related to his or her level of moral development (Mintz \& Morris, 2014). This is why the following on Rest's model shall also be taught to employees. Rest's model has four components: moral sensitivity, moral judgment, moral motivation, and moral character. The first component of ethical decision making is moral sensitivity, which is the ability to be able to realize that one is in a moral situation where an ethical decision must be made. The second is a moral judgment, where one uses prescriptive reasoning to determine possible courses of action, and how each action will affect others. Next is moral motivation, where an individual must determine if they will place ethical values over non-ethical ones. Finally, it comes down to moral character, and if an individual is strong enough to carry out their ethical intentions with ethical action. 


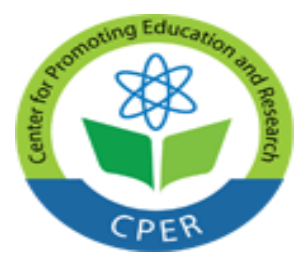

VOL: 5, ISSUE: 3

March/2019

E-ISSN: 2469-6501

Having the company code of ethics and values should give employees a strong ethical foundation to assist in their ethical decision-making process. Employees will also go through Rest's model given scenarios where they can role-play through the four components, which can include diagrams and charts used in a moral judgment to determine what actions are options and who will be affected by each action. In moral motivation, employees can also write out values they believe are the most significant to them (and compare them with the companies to find common ground). Employees can also practice, through role play, standing up to others in scenarios where their moral character may be tested. This way employees will know how to handle themselves in such a situation and have had practice; thus, making it not as frightening and foreign.

\section{Fraud Prevention}

According to the 2014 Report to the Nations on Occupational Fraud and Abuse, a typical corporation loses 5 percent of its revenues to fraud each year, and more than 22 percent of the cases in the survey resulted in losses of at least $\$ 1$ million (ACFE, 2015). In addition to monetary loss from a fraud theft, companies may also occur additional expenses from legal fees and assessed penalties, or in the loss of sales or business due to negative publicity associated with the fraudulent act. Any company can face the possibility of being subjected to fraud, so it is in their best interest to have a fraud prevention program in place.

\section{Control Environment}

The control environment at a company is the foundation for all other components of internal control and provides discipline and structure; its factors include: ethical values and competence of the employees, management's philosophy and operating style, employee development, and the way management assign authority and responsibility (COSO, 2015). A+ Accounting strives to have a culture of honesty and high ethical standards (as witnessed in the core values) that is set from a "tone at the top". Additionally, since A+ Accounting has defined themselves as an ethical business, A+ Accounting trains its employees on the company code of ethics (previously discussed) and on the ethical responsibilities of its employees. A+ Accounting also adheres to a positive work environment, with a management team that has an "open door" policy and purposefully walks around to see how their staff are doing. Management also strives to create a positive work environment by minimizing negative feedback and showing positive reinforcement for good job performance. Management also strives to train employees and promote professional development, so that there is a promotion from within. Thus, employees can see they can have a future within A+ Accounting; again, reducing the rationalization component of the fraud triangle.

\section{Risk Assessment}

Employees at A+ Accounting shall be trained on how to identify sources where fraud can occur and measure the potential risk of each situation. This shall be done through training sessions where various examples of fraudulent acts shall be shown. Employees shall also be trained to think big picture and outside of the box in regard to fraud. Managers shall also be responsible for the assessment of fraud risk, which shall include looking for such risks as fraudulent financial reporting, misappropriation of assets, unauthorized and/or improper receipts and expenditures, and fraud risk by senior management or the board (PriceWaterhouseCoopers, 2003). A+ Accounting has a fraud risk team, composed of individuals from different departments in the company. As fraud risks are identified and researched, the fraud risk team shall assess how the internal controls hold up to each specific risk and report their findings to management (and the Code of Ethics Contact), to make adjustments as needed. Fraud risk assessments will be performed by the fraud risk team when situations change at A+ Accounting. Additionally, these assessments will be performed periodically, and not on a specific timeline known to employees. Thus, employees (and possible fraudsters) do not know when controls will be tested; this will aid in the reduced opportunity for fraud to be committed at A+ Accounting. 


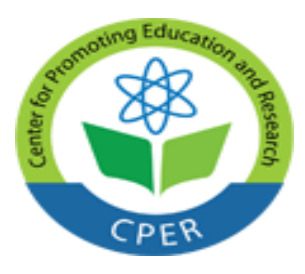

VOL: 5, ISSUE: 3

March/2019

E-ISSN: 2469-6501

(C) Center for Promoting Education and Research (CPER) USA

WWW.cpernet.org

\section{Control Activities}

At A+ Accounting, there will be several control activities to aid in the prevention of fraud; this includes segregation of duties, required authorizations, physical safeguards, independent checks, and documents and records. Here no one employee can have control over an assignment and shall never be handling that assignment alone. Thus, having segregation of duties where the fraud risk assessment has found the possibility for fraud, shall lessen the possibility of occurrences. A+ Accounting has also implemented a system of authorizations so that only certain employees can authorize certain tasks. This puts more responsibility on the authorizing individual (as they know they will be held accountable), limits the number of suspects if there is a situation, and reduces the opportunity for fraud, as it is now easier to find the suspect. This shall also prevent employees from exceeding their authority level. Confidential papers and documents, along with physical checks and cash, shall all be kept under lock as a physical safeguard. This not only prevents the company from losses but also protects their clients' as well. Employees at A+ Accounting shall also be involved in job rotations and be required to take the vacation at least once a year, as an independent check. Allowing another co-worker to do one's job will allow others to see their work and cut down on the perception and opportunity for fraud. A+ Accounting also participates in surprise audits, so employees will not know when they are occurring. In addition to aiding in the reduction of fraud, independent checks shall also assist in catching errors sooner. Finally, at A+ Accounting all account documents and records shall be kept accurately, showing all business transactions that provide an accurate audit trail. This will aid in the easy detection of fraud, along with routine audit sampling to look for any anomalies. These control activities shall instil in employees that management is committed to preventing fraud and holding its employees (and company as a whole) to high ethical standards.

\section{Whistleblower System}

At A+ Accounting, employees are encouraged to report ethical and legal violations to aid in the reduction of fraud and unethical behavior. Upper-level management shall encourage its ethical commitment through memos and newsletters to company employees; here, the whistleblower system shall also be regularly discussed to acknowledge its importance. Additionally, management and the Code of Ethics Contact shall have an open-door policy to its staff regarding employee complaints or concerns, and management shall be trained on how to encourage openness among staff. If employees wish to report an act anonymously, the may call the Whistleblower hotline (1-800-NO-FRAUD) or leave a note in the Whistleblower mailbox located in the main lobby. All reports shall be investigated quickly, and thoroughly, by the Code of Ethics Contact, and management, with the results being reported to a higher authority, as "inaction is the best way to create cynicism regarding the seriousness of an organization's ethics policy" (Ravishankar, 2003). All new employees shall be given a card with the Whistleblower hotline number on it, shown (in person) where the Code of Ethics Contact's office is, and where the mailbox is located.

\section{Conclusion}

A+ Accounting shall conduct an annual ethics survey given to its employees at the end of each year, including (but not limited to) such questions as: how the employees feel the ethical tone at the company is, if employees know how and where to report an ethical violation or suspected fraud, if they know the company values, if they know the purpose of the code of ethics, and other such ethical questions. The answers will allow the Code of Ethics Contact and management to review what items staff should be further trained on during the upcoming year, along with what internal controls need updating. Additionally, at this time, the Code of Ethics Contact and management may also want to update A+ Accounting's code of ethics if they feel it is not reflective of where the company is heading or if there have been significant company changes that require updates. In accounting, integrity is its own reward as it builds trust in client relationships and helps honor the public trust that is the foundation of the profession (Mintz \& Morris, 2014). Thus, A+ Accounting not only strives to be an ethical business, governed by its code of ethics and values but also strives to have happy, satisfied, professional employees, who consider themselves 


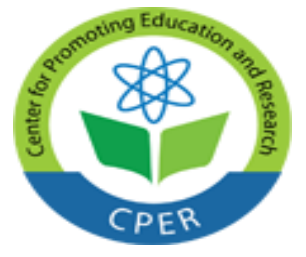

VOL: 5, ISSUE: 3

March/2019

https://ijbassnet.com/

E-ISSN: 2469-6501

(C) Center for Promoting Education and Research (CPER) USA

WWW.cpernet.org

part of the A+ Accounting team. All of which should aid in the substantial reduction (or elimination) of fraud occurrences and unethical behavior at A+ Accounting.

\section{References}

ACFE. (2015). Cost of fraud: is your company at risk? Retrieved from: http://www.acfe.com/cost-of-fraud.aspx

AICPA. (2015). Professional judgment. Retrieved from: http://www.aicpa.org/interestareas/frc/pages/professionaljudgment.aspx

COSO. (2012). Enhancing board oversight; Avoiding judgment traps and biases. Retrieved from:

http://www.coso.org/documents/COSO-EnhancingBoardOversight r8 Web-ready\%20(2).pdf

COSO. (2015). Internal control - integrated framework. Retrieved from:

http://www.coso.org/documents/Internal\%20Control-Integrated\%20Framework.pdf

DeHart, J. (2011). What do core values do? Why do I need them? Retrieved from:

http://www.johndehartblog.com/2011/09/22/what-do-core-values-do-why-do-i-need-them-well-at-least-the-top-11reasons-why/

FASAB. (2015). Current FASAB handbook. Retrieved from: http://www.fasab.gov/accountingstandards/authoritative-source-of-gaap/accounting-standards/fasab-handbook/

Fazel. H. (2011). How professional judgment and professional skepticism are different in application? Retrieved from: http://pakaccountants.com/profession-judgement-and-professional-skepticism-difference-inapplication/

NIH. (2015). Gifts from outside sources. Retrieved from: https://ethics.od.nih.gov/topics/giftsout.htm

Mintz, S. M., \& Morris, R. E. (2014). Ethical obligations and decision making in accounting: Text and cases (3rd ed.). New York, NY: McGraw-Hill. ISBN13: 9780077862213

Maxwell, John. C. (2007). The 21 irrefutable laws of leadership. (10the ed.). Nashville, TN: Thomas Nelson. ISBN: 9781418526153

PCAOB. (2012). PCAOB publishes staff audit practice alert on maintaining and applying professional skepticism in audits. Retrieved from: http://pcaobus.org/News/Releases/Pages/12042012_SAPA10.aspx

Ravishankar, L. (2003). Encouraging internal whistleblowing in organizations. Retrieved from:

http://www.scu.edu/ethics/publications/submitted/whistleblowing.html

PriceWaterhouseCoopers. (2003). Key elements of antifraud programs and controls. Retrieved from: http://www.tdot.state.tn.us/internalaudit/documents/PwCAntifraudWP.pdf 